\title{
KNOWLEDGE MANAGEMENT IN HIGHER EDUCATION : APPLICABILITY OF LKMC MODEL IN SAUDI UNIVERSITIES
}

\author{
Farzana Shafique \\ Universityof Dammam, Saudi Arabia
}

\begin{abstract}
This paper stresses on the need of using Knowledge Management (KM) in the higher education institutions of Saudi Arabia. The paper is based on the literature review and personal experience of the author in the education sector.

The paper aims at highlighting the importance of $K M$ for the educational institutions particularly for developing countries. It also reviews the readiness of Saudi Arabia for KM application by illustrating different development initiatives taken by the Saudi government in different sectors. However, the literature also identifies many barriers on the way.

Keeping the importance of KM for the higher education institutions in view, this paper proposes to adopt the model of Library Knowledge Management Center (LKMC) with needed modifications for Universities of Saudi Arabia. This LKMC model was proposed by Parker, Nitse, and Flowers (2005) for the small business corporate for providing the Knowledge Management (KM) and Competitive Intelligence (CI) services. The paper discusses different components of the LKMC model and their relevance to the education sector.
\end{abstract}

\section{KEYWORDS}

Knowledge Management; Higher Education; LKMC; Kingdom of Saudi Arabia

\section{INTRODUCTION}

Many of us simply do not think in terms of managing knowledge, but we all do it. Each of us is a personal store of knowledge with training, experiences, and informal networks of friends and colleagues, whom we seek out when we want to solve a problem or explore an opportunity. Essentially, we get things done and succeed by knowing an answer or knowing someone who does (NHS National Library for Health, 2005).

Many researchers believe that knowledge sharing is the vital element in KM (Firestone, 2001). Thus, $\mathrm{KM}$ is a process where organizations have formulated ways in the attempt to recognize and archive knowledge assets within the organization that are derived from the employees of various departments or faculties and in some cases, even from other organizations that share the similar 
area of interests or specialization (Bouthillier, \& Shearer, 2002). In this context, an institution wide approach to KM can largely facilitate the knowledge sharing process; both explicit and tacit, and the subsequent surge benefits

Purpose: The paper aims at identifying the benefits of $\mathrm{KM}$ for education sector. It focuses on highlighting the case of developing nations and reviews the current practices of KM in these nations. The paper also analyses the readiness of Saudi Arabia for KM and it proposes adopting the Library Knowledge Management Center (LKMC) model for higher education institutions of Saudi Arabia.

Methodology: The paper is based on review of literature and author's personal teaching and administrative experience in higher education. It discusses different components of LKMC model proposed by Parker, Nitse, and Flowers (2005). For literature search, standard sources of scholarly information were used e.g., Library Literature, World Wide Web search engines and scholarly online databases accessible through University of Dammam portal i.e., ScienceDirect, Emerald, and many more.

\section{Need of KM in Higher Education Institutions}

Laal (2011) has stressed on the use of Corporate Sector's Knowledge Management (KM) practices in the higher education institutes. He has reviewed many studies to supplement his claim and has mentioned that $\mathrm{KM}$ is a systematic process by which knowledge needed for an organization to succeed is created, captured, shared, and leveraged. Nowadays, the pace of evolution has entered a rapid speed; those who cannot learn, adapt, and change from moment to moment simply won't survive. While discussing the case of developed world, Laal has mentioned that current higher education institutes recognize their valuable intelligences and have adopted their changing role in a society.

Rowley (2000) believes that educational institutes particularly higher education are said to be in the knowledge business since they are involved in knowledge creation, dissemination and learning. Kidwell, Linde, and Johnson (2000) also stressed on the use of KM techniques and technologies in higher education and called it as vital as it is in the corporate sector. They mentioned that educational institutes i.e., colleges and universities have significant opportunities to apply KM practices to support every part of their mission, from education to public service to research. Effective use of knowledge capital in educational institutes can lead to better decisionmaking capabilities, reduced "product" development cycle time, improved academic and administrative services, and reduced costs. Similarly, Ramanigopal (2012) said that higher education has significant opportunities to apply knowledge management practices to support every part of their mission, from education to learning society to research and development.

Many educational institutions are spending millions of dollars into information technology without considering the effective integration of the same into shared decision-making processes to improve academics, operations, and planning. On the other hand, many of these educational institutions are farther along in developing an "information culture", yet lag behind in their "technology culture". Here, the Knowledge Management (KM) practices can provide great help to the educational institutes to overcome this problem. Because the primary benefit of the KM is that it actively addresses both the "technology culture" and the "information culture" at an institution, and seeks to advance both simultaneously (Petrides, \& Nodine, 2003). Omona and 
Lubega (2012) proposed conceptual framework for enhancing knowledge management (KM) in higher education in order to advance strategic goals and direction. The key dimensions of their proposed framework were tested using case studies of higher education institutions (HEI) in Uganda to examine relative use and effectiveness of the current existing KM enabling ICT tools and technologies. Their study also aimed at identifying key KM processes and determining critical success factors.

Gopal and Shobha (2012) studied the general understanding of students about Knowledge Management, the opportunities available for their Knowledge Management and KM practices adopted by them in their higher education. They recommended integrating the KM in university teaching and learning process. Steyn (2004) stressed on the importance of KM in the higher education institutions and proposed a model for effective implementation of KM in the higher education institutions. Steyn believed that successful organizations are knowledge creating organizations, which produce, disseminate and embody new knowledge in new products and services

\section{KM in Higher Education: The Case of Developing Countries}

The trend of using, KM in educational institutions is also prevailing in the developing world. For example, Abass, Hayat, Shahzad, and Riaz, (2011) in a recent descriptive survey revealed the acceptability of KM practices in public sector of Pakistan. They surveyed two educational institutes, e.g., secondary education board and a higher education institute. During their research, they found positive perceptions of employees towards organizational culture, KM practices, and organizational performance. Their descriptive results showed the positive trend of each of the variable. According to the employees working in different organizations under government sector of Pakistan, the culture of their respective organizations encourages and provides opportunity for the communication of ideas and knowledge; organization encourages and rewards the sharing of

knowledge. Moreover, performance of the surveyed organizations was satisfactory in terms of employees' satisfaction, their retention, and operating costs etc.

Yusoff, Mahmood, and Jaafar (2012) explored the relationship of KM implementation and KM enabler among members in a community college of Malaysia. The researchers identified the possibility of developing a socioeconomic center at the community colleges with strong links to the government, coordinated by a management, which actively supports the technology and knowledge transfer and provides communities with facilities and services. This attracts mainly local communities who expect benefits and synergies from these colleges. The researchers believed that their research had just opened a space to improve the KM. In future researchers would recognize the main activities in community college that can be defined clearly as part of $\mathrm{KM}$ and then they would further propose a framework for those activities that can be used practically by the staff of community college. Similarly, Chumjit (2012) explored the application of knowledge management (KM) in the higher education institutions of Thailand. Based on a qualitative research design, Chujit studied four autonomous universities of Thailand and reported that the four universities have tried to create new knowledge (both tacit and explicit knowledge). New methods for improving teaching, research, administration, and strategic planning have been created and KM has been successfully applied within various sections and departments. 


\section{KM Initiatives in Saudi Arabia}

The Knowledge Management is an emerging concept in Saudi Arabia. Many new KM initiatives have been taken by the Government of Saudi Arabia. The remarkable example is of "Knowledge Economic City" (KEC) project at Madinah. The KEC is aimed to serve Saudi Arabia's economic diversification strategy and reviving Madinah's role as a center for the Islamic knowledge and a global knowledge and culture center. Through this project, the Saudi government aims to enhance the quality of life and economic prosperity in the region. It would create many investment and development opportunities across all the sectors through commercial, residential, educational, and hospitality projects (Knowledge Economic City, 2012).

Yaghi and Zamzami, 2014) stressed on the importance and need of knowledge management in the higher education institutions of Saudi Arabia. They highlighted the major constraints on the way and provided a framework for applying the concept of KM in higher education institutions of Saudi Arabia. They suggested that the higher management in these educational institutions should adopt the strategic thinking of knowledge management. They also stressed on the need of knowledge sharing among employees/workers of these institutions, so that the tacit/implicit knowledge can be explicit. Al-Hussain (2011) probed the Barriers to Knowledge Management in Saudi Arabia through an intensive research. The author's research and analysis led to the identification of barriers related to organization (19 barriers), technology (24 barriers), leadership (32 barriers), and learning (22 barriers).

Despite all these barriers and hurdles, government policy documents clearly indicate their awareness of these issues and draws framework for overcoming the same. For example, the Ministry of Education (2004) documents identifies the weaknesses in the education system and stresses on the need of knowledge intensive education system. Alsereihy, Alyoubi, and El-Emary (2012) reviewed some case studies on KM implementation in Saudi Arabia. The reviewed studies were related to different ongoing initiatives/projects in Saudi Arabia; such as schools for girls, public sector firms, oil, and chemical factory and construction firms. They stressed that the initiatives would be successful only when more people have participated in the initiative and they have exchanged their views thus creating knowledge. They also stressed on the need of using Social media for knowledge sharing purpose. Similarly, Abokhodiar (2013) proposed a model for the implementation of KM at the Women's Branch of the Institute of Public Administration in the Kingdom of Saudi Arabia. She mentioned that several perspectives urged the need of KM implementation at WIPA. According to her, the most important one was the current status of the workforce and the generation gap between faculty members. This could result in a loss of a portion of the accumulated knowledge and experiences of the intellectual capital of WIPA. Her proposed model aimed to provide an integrated strategy of KM implementation at WIPA by 2018 .

\section{Library Knowledge Management Center (LKMC) Model for Higher Education Institutions of the Saudi Arabia}

Parker, Nitse, and Flowers (2005) foresaw a dynamic and influential role of libraries and information centers for providing $\mathrm{KM}$ and $\mathrm{CI}$ services to the other sectors. Competitive Intelligence (CI): Organizations use the CI process to gather information, to add value to it through analysis, and to report the findings to managers to solve a wide variety of problems or satisfy requests for information. 
Although they stressed on the applicability of LKMC (Library Knowledge Management Center) model for small business sector, however, their proposal has equally great potential of applicability for not-for-profit organizations particularly education sector. Libraries are the integral part of education sector; on the other hand, libraries are struggling for their own survival in this digital world and arena of escalating fiscal resources for libraries. In this perspective, the role of libraries as LKMC will not only benefit the libraries but it would also be a great contribution to education sector.

\section{Components of a Library Knowledge Management Center (LKMC)}

After a comprehensive review of related literature, Parker, Nitse, Flowers (2005) believe that several steps must be undertaken for libraries to act as KM centers, such as developing domain ontologies to help categorize resources for specific clients; thorough understanding of the domain; Domain ontology provides a specification of a shared conceptualization to be used for formulating knowledge-level theories about a domain (Domingue and Motta, 1999). Thus, they have to develop the general and then specific domain terms. The effective use of needs identification tools like key intelligence topics (KITs) is also required. The KITs process can help to identify and define critical intelligence needs (Herring, 1999).

Similarly, the Multi-Class Interest Profile (M-CLIP) can also be developed in-place or parallel to KITs; the M-CLIP provides a strategically aligned framework based on the various types of information needs in order to insure that key items within each domain are accounted for. The KITs and M-CLIP techniques are generally used in conjunction with Competitive Intelligence (CI) etc. (Parker \& Nitse, 2001).

Moreover, Parker and Nitse (2001) suggested the hiring of a specialist trained in knowledge engineering, a specialist trained in knowledge engineering who can greatly assist the specification of key concepts for the domain ontology. The use of natural language processing techniques for determining the contents of each digital document; collecting and managing internal and external sources or even subscribing databases from third party vendors or other informal online sources are also suggested as important elements of LKMC model. They further ascertained on the management of internally generated knowledge, which refers to that knowledge within the minds of their employees. In order to handle such knowledge, the system should provide an interface to allow users to store information that will be sharable with other users of the system through customized and interactive search interfaces. Furthermore, the emphasis should also be on preserving and further utilizing the users' search feedback while searching in library catalog. The final suggestion was the utilization of Semantic Web for semantically linking and then retrieving or accessing the library's resources. The Semantic Web promises to give well-defined meaning to the web by incorporating into web documents well-defined semantics. Agents should be able to determine the semantic linkages between web resources by following links from web pages to topic-specific ontologies.

They further claimed that Results can be delivered on a push or pull basis to provide ongoing competitive (and other) intelligence. For bearing the expanses of the center and for its long term sustainability, they further suggested that a subscription fee can be charged from the clients for providing the user specific services of LKMC. The alternative approaches such as web portals for individuals or communities to access the internet and to conduct research on topics of interest to them can also be utilized for making LKMC more effective (Sadeh and Walker, 2003). However, 
for coping with the new developments after the proposed model of Parker and Niste (2005), one should focus on providing KM and Environment Intelligence (EI) services to the end users. According to McGee and Sawyer, (2003), the environment intelligence is an encompassing concept covering disciplines such as business intelligence, competitor intelligence, competitive intelligence, and social intelligence. The environment intelligence is the collection of information about events and changes happening in the external environment of an organization by using legal and ethical information gathering channels and techniques. The external environment here refers to relevant social and physical factors outside the typical boundaries of an organization which may affect its performance and future survival.

\section{CONCLUSIONS AND RECOMMENDATIONS}

The review of the literature made in this article has supported the idea of using knowledge management in the higher education institutions. It shows that the now developing countries are also becoming aware of knowledge management. Many new initiatives have been taken in this regard. Saudi Arabia is also emerging as an active KM enabler from the developing world. Many new KM projects particularly the initiation of "Knowledge Economic City" (KEC) project at Madinah shows the Saudi Arabia's readiness for knowledge society. In this context, the paper proposes implementing the LKMC model with necessary modifications in the universities of Saudi Arabia. It is believed that if implemented truly, it would boost up the higher education of Saudi Arabia. It is suggested that the system/center proposed by Parker and Niste (2005) should look at competitive environment in broader perspective. Besides, the Knowledge Management (KM) services, it should also be able to provide Environment Intelligence (EI= Competitive, Competitor, and Social Intelligence) services to the educational administrators.

\section{REFERENCES}

[1] Abass, F., Hayat, M., Shahzad, A., \& Riaz, A. (2011). Analysis of Knowledge Management in the Public Sector of Pakistan. European Journal of Social Sciences, 19, (4), 471-478.

[2] Abokhodiar, E. S. (2013). Knowledge management implementation at the Women's Branch of the Institute of Public Administration in Saudi Arabia: A Proposed Model. Excellence in Higher Education, 4: 119-128

[3] Bouthillier, F. \& Shearer, K. (2002). Understanding knowledge management and information management: the need for an empirical perspective. Information Research, 8(1).

[4] Chumjit, S. (2012). Knowledge management in higher education in Thailand. ProQuest, UMI Dissertations Publishing.

[5] Domingue, J. \& Motta, E. (1999). A knowledge-based news server supporting ontology-driven story enrichment and knowledge retrieval. In Proceedings of the 11th European Workshop on Knowledge Acquisition, Modeling, and Management (EKAW 1999), Dagstuhl Castle, Germany, SpringerVerlag, Berlin, pp. 103-20.

[6] Firestone, J. M. (2001). Key Issues in Knowledge Management. Knowledge and Innovation. Journal of the KMCI, 1(3), 8-38.

[7] Herring, J. P. (1999). Key intelligence topics: a process to identify and define intelligence needs. Competitive Intelligence Review, 10(2), 4-14.

[8] Kidwell, J. J., Linde, K. M. V., \& Johnson, S. L. (2000). Applying corporate knowledge management practices in higher education. Educause Quarterly, 4, 28-33.

[9] Laal, M. (2011). Knowledge management in higher education. Procedia Computer Science, 3, 544549 . 
[10] McGee, J. E. \& Sawyer, O. O. (2003). Uncertainty and information search activities: A study of owner-managers of small high-technology manufacturing firms. Journal of Small Business Management, 41(4), 385-401.

[11] NHS National Library for Health. (2005). What is knowledge management? ABC of Knowledge Management; 1-68.

[12] Parker, K. R. \& Nitse, P. S. (2001). Improving competitive intelligence gathering for knowledge management systems. In Proceedings of the 2001 International Symposium on Information Systems and Engineering - ISE'2001-Workshop: Knowledge Management Systems: Concepts, Technologies and Applications, Las Vegas, Nevada.

[13] Parker, K. R., Nitse, P. S., Flowers, K. A. (2005). Libraries as knowledge management centers. Library Management, 26(4/5), 176-189.

[14] Petrides, L. A. \& Nodine, T. R. (2003). Knowledge management in education: Defining the landscape. Retrieved October 25, 2014, from: http://iskme.path.net/kmeducation.pdf

[15] Rowley, J. (2000). Is Higher Education Ready for Knowledge Management? The International Journal of Educational Management, 14(7), 325-333.

[16] Sadeh, T. \& Walker, J. (2003). Library portals: toward the Semantic Web, New Library World, 104(1184/1185), 11-19.

[17] Yusoff, M. Y. M., Mahmood, A. K., \& Jaafar, J. (2012). A Study of KM process and KM enabler in a Malaysian Community College. Journal of Knowledge Management Practice, 13(1). Retrieved October 24, 2014, from: http://www.tlainc.com/articl297.htm

[18] Knowledge Economic City. (2012). The New Gateway to Madinah. Retrieved December 12, 2014, from: http://www.madinahkec.com/en/project/kec

[19] Yaghi, K., \& Zamzami, O. A. (2014). Obstacles of Implemeting Knowledge Management in the High Education Institutes - Saudi Arabia (Analytical study). International Multilingual Academic Journal, $1(1)$.

[20] Al-Hussain, A. Z., (2011). Barriers to Knowledge Management in Saudi Arabia. Unpublished Dissertation, The George Washington University, Proquest. 213 pages; 3481091. Ministry of Education. (2004). The Development of Education, 47th Session of the International Conference on Education, September 8-11, 2004, Geneva.

[21] Alsereihy, H. A., Alyoubi, B. A., \& El-Emary, I. M. M. (2012). Effectiveness of Knowledge Management Strategies on Business Organizations in KSA: Critical Reviewing Study. Middle-East Journal of Scientific Research, 12 (2): 223-233.

[22] Omona, W., \& Lubega, J. T. (2012). Enhancing Knowledge Management Using ICT in Higher Education: An Empirical Assessment, Journal of Knowledge Management Practice, 13(3).

[23] Gopal, V., \& Shobha, K. (2012). Knowledge management in higher education. Asian Journal of Research in Social Sciences and Humanities, 2(8). Retrieved December 12, 2014, from: http://www.indianjournals.com/ijor.aspx?target=ijor:ajrssh\&volume $=2 \&$ issue $=8 \&$ article $=006$

[24] Ramanigopal, C. (2012). Knowledge management strategies in higher education. International Journal of Advanced Research in Management (Ijarm), 3(1), pp. 20-29.

[25] Steyn, G.M. (2004), Harnessing the power of knowledge in higher education, Educational Development, 124(4), 615-630. 